\title{
Three-phase inverter-connected DG-units and voltage unbalance
}

\author{
Bart Meersman*, Bert Renders, Lieven Degroote, Tine Vandoorn, Lieven Vandevelde \\ Electrical Energy Laboratory (EELAB), Department of Electrical Energy, Systems and Automation (EESA), Ghent University, Sint-Pietersnieuwstraat 41, B-9000 Ghent, Belgium
}

\section{A R T I C L E I N F O}

\section{Article history:}

Received 6 November 2009

Received in revised form

24 September 2010

Accepted 28 November 2010

Available online 28 December 2010

\section{Keywords:}

Voltage unbalance

Distributed generation

Voltage-source inverter control strategies

three-phase inverter

\begin{abstract}
A B S T R A C T
The increasing presence of single-phase distributed generators and unbalanced loads in the electric power system may lead to unbalance of the three phase voltages, resulting in increased losses and heating. The distribution network operators (DNOs) are increasingly being challenged to maintain the required power quality. To reduce voltage unbalance DNOs are seeking to connect larger DG units to the three phases instead of a single-phase connection. The three-phase connection can be realised by three single-phase inverters or by a three-phase inverter. Each inverter topology can be implemented with different control strategies. The control can be equiped with active power filtering functions which can improve the power quality. In this paper, the effect of connecting DG units by means of a three-phase connection instead of a single-phase connection on voltage unbalance is studied. Besides two commonly used control strategies, two other control strategies that combine DG and active power filtering functions are implemented and their effect on voltage unbalance is studied. The last two control strategies lead to the reduction of voltage unbalance such that the voltage requirements are maintained.
\end{abstract}

(C) 2010 Elsevier B.V. All rights reserved.

\section{Introduction}

Ideally, the generated voltages in three-phase power systems are symmetrical. However, the resulting voltages at the point of common coupling (PCC) and at the point of connection (POC) can be unbalanced for several reasons. The nature of the unbalance includes unequal voltage magnitudes at the fundamental system frequency (under- and over-voltage), fundamental phase angle deviation and unequal levels of harmonic distortion between the phases [32].

Unbalance can result in adverse effects on equipment and on the distribution system. An unbalanced distribution system will be subjected to more losses and heating effects. Voltage unbalance can also have negative effects on equipment such as induction motors, power electronic converters and adjustable speed drives $[17,16,32,22,29]$. Avoiding these negative effects requires maintaining a balanced voltage at the POC.

The distribution network operators (DNOs) are increasingly being challenged to maintain the required power quality. DNOs are imposing to connect larger distributed generation (DG) units (viz $>3.6 \mathrm{kVA}$ in Belgium) to the three phases instead of one to reduce voltage unbalance.

Improving voltage unbalance can be achieved by installing three-phase systems especially designed to improve the power quality. An example of such a three-phase system is a Unified Power

\footnotetext{
* Corresponding author. Tel.: +32 926434 42; fax: +32 92643582 .

E-mail address: Bart.Meersman@UGent.be (B. Meersman).
}

Quality Conditioner (UPQC) which is controlled to deliver a small amount of negative-sequence current into the grid to decrease the negative-sequence voltage component $[33,13]$.

There are several possible topologies to connect DG units to a three-phase distribution network. The most common practice nowadays is to use three single-phase inverters which share a common dc-bus and the corresponding dc-bus voltage controller $[8,5,7,27]$. This will result in a system with power factor near to one as three single-phase current controllers are used which result in currents in phase with the grid voltage. Another possibility is a three-phase four-wire inverter [4,19,9]. Both topologies can be controlled by using different control strategies [23,24].

Presently, two control strategies are frequently used. For threephase systems consisting of three single-phase inverters with a common dc-bus, a single-phase sinusoidal control strategy is used [8,5,7]. Each single-phase inverter injects a sinusoidal current in phase with the respective phase voltage. Another frequently used control strategy for three-phase inverters is the positive-sequence control strategy $[4,34,19,3,2]$. The inverter is controlled such that it injects a positive-sequence current. These two control strategies will not deteriorate the voltage unbalance but will neither improve it.

The voltage unbalance can be improved when the control strategies are altered such that they possess active power filtering functions $[14,28]$. Adding active power filtering functions to the control strategy of inverter-connected DG units can lead to an improved power quality [15]. Therefore in this paper, the two previous commonly used control strategies are equiped with active power filtering functions. The single-phase sinusoidal con- 
Table 1

Supply voltage requirements according to EN 50160.

\begin{tabular}{ll}
\hline Parameter & Characteristics \\
\hline Power frequency & LV, MV: mean value of fundamental \\
& measured over $10 \mathrm{~s} . \pm 1 \%(49.5-50.5 \mathrm{~Hz})$ for \\
& $99.5 \%$ of week $-\% /+4 \%(47-52 \mathrm{~Hz})$ for $100 \%$ \\
& of week \\
& $V_{\text {nom }}=230 \mathrm{~V}, \pm 10 \%$ for $95 \%$ of week; mean \\
& 10 min rms values \\
Voltage magnitude variations & Majority: duration $<1$ s, depth $<60 \%$. Locally \\
Supply voltage dips & limited dips caused by load switching on: \\
& $10-50 \%$ \\
Supply voltage unbalance & Negative-sequence voltage component \\
& $<2 \%$ for $95 \%$ of the week, mean 10 min rms \\
& values \\
\hline
\end{tabular}

trol strategy can be improved by adding a signal to the reference current, this signal results in a resistive behaviour towards voltage disturbances independently of the input power [26,25]. An alternative three-phase control strategy is the three-phase damping control strategy which is presented in this paper. Besides injecting positive-sequence power, the three-phase damping control strategy behaves resistively towards the zero- and negative-sequence voltage component (independently of the input power) which will lead to an improved voltage unbalance.

Instead of installing three-phase systems especially designed to improve the power quality, the increasing presence of inverterconnected DG units can be used to decrease voltage unbalance by implementing the appropriate control strategy. In this paper, the influence of the different control strategies for DG-units on voltage unbalance is studied.

\section{Voltage unbalance factor}

There are three commonly used definitions of voltage unbalance, developed by NEMA (National Equipment Manufacturer's Association), IEEE and the power community, respectively $[21,6]$. In this paper, the percentage voltage unbalance factor (\% VUF) is chosen as a measure to evaluate the voltage unbalance.

Based on the theory of symmetrical components, voltage unbalance can be divided into two parts corresponding to the negative-sequence and the zero-sequence component of the voltage. For instance, induction motors are very sensitive to the negative-sequence voltage component as the negative-sequence impedance is small. Even a small negative-sequence voltage component leads to large currents and thus increased losses. On the other hand, the zero-sequence component of the voltage can result in currents flowing in the neutral conductor which causes heating and zero-point shifting [12,28].

The voltage unbalance factor (\% VUF) is given by the ratio of the magnitudes of the fundamental negative-sequence voltage component to the positive-sequence voltage component:

$\% \mathrm{VUF}=\frac{V_{2}}{V_{1}} 100$.

The zero-sequence voltage unbalance factor $\left(\% \mathrm{VUF}_{0}\right)$ is given by the ratio of the magnitudes of the zero-sequence voltage component to the positive-sequence voltage component:

$\% \mathrm{VUF}_{0}=\frac{V_{0}}{V_{1}} 100$.

The DNOs are obliged to maintain the voltage to certain requirements. The supply voltage requirements of public distribution systems in Belgium are based on the standard EN50160 [1]. An overview of the most important aspects of this standard is given in Table 1. The two most important parameters for this paper concern voltage magnitude variations and supply voltage unbalance.

\section{Voltage-source inverter control strategies}

The control of an inverter can be divided in two parts: the dc-bus voltage controller and the current controller. The dc-bus voltage controller maintains the balance between the ac- and dc-power and outputs the fundamental input conductance $g_{1}$ which is a measure for the power injected by the DG unit [20]. $g_{1}$ is positive when the inverter injects power and negative when the inverter absorbs power. In case of an unbalance between the ac- and dc-power, the dc-bus voltage will deviate from its reference value. The dc-bus voltage controller will react by changing the fundamental input conductance $g_{1}$ in order to restore the balance. This input conductance is used to derive the reference values for the different currents in the respective phases. The current controller makes sure that the inverter provides the reference current. The possible error between the reference current and the measured current is eliminated by a PI-controller which outputs the duty ratio for the switches.

As stated in the introduction, there are two possible topologies to connect the DG units to a three-phase distribution network. The first possibility is to use three single-phase inverters which share a common dc-bus and the corresponding dc-bus voltage controller. The second possibility is using a three-phase inverter. These two topologies can be combined with two current control strategies, which will be described further in this section. The control strategies differ in the way the reference values for the current are determined.

First, the two frequently used control strategies will be discussed, namely the single-phase sinusoidal control strategy and the (three-phase) positive-sequence control strategy. Then, the active power filter equiped control strategies will be handled: the single-phase control strategy behaving resistively towards voltage disturbances and the three-phase damping control strategy. The last two control strategies are not presently used but when implemented they could lead to an improved voltage unbalance as discussed further in this paper.

\subsection{Single-phase sinusoidal control strategy}

The reference values for the different currents in case of a sinusoidal current controller are:

$i_{x}=g_{1} \sin \left(\theta_{x}\right)$

with $x=a, b$ or $c$ and where $g_{1}$ is the fundamental input conductance. Small letters denote pu quantities. $\theta_{x}$ is the phase angle of phase voltage $x$. The current injected by the DG is in phase with the respective phase voltage (power factor equal to one). This can be achieved by using three single-phase inverters or by using a three-phase inverter and three single-phase phase-locked loop (PLL) systems. In both possibilities the phase angles of all three phase voltages are obtained such that a reference current can be obtained which is in phase with the respective phase voltage ( $\mathrm{cf}(3))$.

In order to achieve a better understanding on the influence of the sinusoidal control strategy on voltage unbalance, a symmetrical components model is deduced. Based on (3), the complex form of the injected currents can be written as:

$\underline{i}_{x}=g_{1} \exp \left(j \theta_{x}\right)$

This equation can be converted to symmetrical components:

$$
\begin{aligned}
& \underline{i}_{0}=\frac{1}{3} g_{1}\left[\exp \left(j \theta_{a}\right)+\exp \left(j \theta_{b}\right)+\exp \left(j \theta_{c}\right)\right] \\
& \underline{i}_{1}=\frac{1}{3} g_{1}\left[\exp \left(j \theta_{a}\right)+\exp \left(j\left(\theta_{b}+\frac{2 \pi}{3}\right)\right)+\exp \left(j\left(\theta_{c}-\frac{2 \pi}{3}\right)\right)\right] \\
& \underline{i}_{2}=\frac{1}{3} g_{1}\left[\exp \left(j \theta_{a}\right)+\exp \left(j\left(\theta_{b}-\frac{2 \pi}{3}\right)\right)+\exp \left(j\left(\theta_{c}+\frac{2 \pi}{3}\right)\right)\right]
\end{aligned}
$$




\subsection{Positive-sequence control strategy}

The most common practice with three-phase inverters is that a positive-sequence current is injected. In three-phase distributed power generation systems, the phase angle of the utility voltage is commonly detected by using a three-phase PLL. Most threephase PLL systems use the coordinate transformation $a b c \rightarrow d q$. The phase angles resulting from this PLL correspond with the positivesequence component of the grid voltage $[30,31,18]$. When using this three-phase PLL, only a positive-sequence current is injected in the grid. The symmetrical components model of this control strategy is:

$\underline{i}_{0}=0$
$\underline{i}_{1}=g_{1}$
$\underline{i}_{2}=0$

\subsection{Single-phase control strategy behaving resistively towards voltage disturbances}

To improve the behaviour of the single-phase sinusoidal current control, (3) may be extended by adding an extra signal to the reference value for the inductor current. The new reference values for the inductor current are:

$i_{x}=g_{1} \sin \left(\theta_{x}\right)+g_{\mathrm{d}}\left(v_{x}, 1-1\right) \sin \left(\theta_{x}\right)$

where $g_{d}$ is the damping input conductance and has the opposite sign of $g_{1}$ in DG applications $\left(g_{\mathrm{d}}>0\right), v_{x}, 1$ is the fundamental component of the grid voltage.

The first term of (7) can be interpreted as the steady-state value of the fundamental component of the inductor current. This term is adapted by the bus-voltage controller in order to balance the power exchanged with the grid with the input power of the DG unit. The second term will react on every deviation of the fundamental grid voltage $v_{x}, 1$ from its steady-state value [26].

The current originating from voltage disturbances is determined by the programmable damping input conductance $g_{\mathrm{d}}$. This conductance is chosen maximal to retain the maximal effect $\left(\right.$ viz $g_{\mathrm{d}}=1 \mathrm{pu}$, which is maximal in a digital control).

This control strategy has already been implemented on a singlephase full-bridge inverter where it proved to yield an improved voltage dip immunity [26].

In this paper, harmonic distortion will not be considered. Based on (7), the complex form of the injected currents can be written as:

$\underline{i}_{x}=\left[g_{1}+g_{\mathrm{d}}\left(v_{x, 1}-1\right)\right] \exp \left(j \theta_{x}\right)$

This equation can be converted to symmetrical components:

$$
\begin{aligned}
\underline{i}_{0} & =\frac{1}{3}\left\{\left(g_{1}-g_{\mathrm{d}}\right)\left[\exp \left(j \theta_{a}\right)+\exp \left(j \theta_{b}\right)+\exp \left(j \theta_{c}\right)\right]+3 g_{\mathrm{d}} \underline{v}_{0}\right\} \\
\underline{i}_{1} & =\frac{1}{3}\left\{( g _ { 1 } - g _ { \mathrm { d } } ) \left[\exp \left(j \theta_{a}\right)\right.\right. \\
& \left.\left.+\exp \left(j\left(\theta_{b}+\frac{2 \pi}{3}\right)\right)+\exp \left(j\left(\theta_{c}-\frac{2 \pi}{3}\right)\right)\right]+3 g_{\mathrm{d}} \underline{v}_{1}\right\} \\
\underline{i}_{2} & =\frac{1}{3}\left\{( g _ { 1 } - g _ { \mathrm { d } } ) \left[\exp \left(j \theta_{a}\right)+\exp \left(j\left(\theta_{b}-\frac{2 \pi}{3}\right)\right)\right.\right. \\
& \left.\left.+\exp \left(j\left(\theta_{c}+\frac{2 \pi}{3}\right)\right)\right]+3 g_{\mathrm{d}} \underline{v}_{2}\right\}
\end{aligned}
$$

As $\theta_{x}$ is the phase angle of the grid voltage, it is possible to write $\theta_{x}$ as a function of $\underline{v}_{0}, \underline{v}_{1}$ and $\underline{v}_{2}$.

\subsection{Three-phase damping control strategy}

An alternative for the positive-sequence control strategy can be found in the three-phase damping control strategy. The preferred reaction of the control strategy on voltage unbalance is a resistive

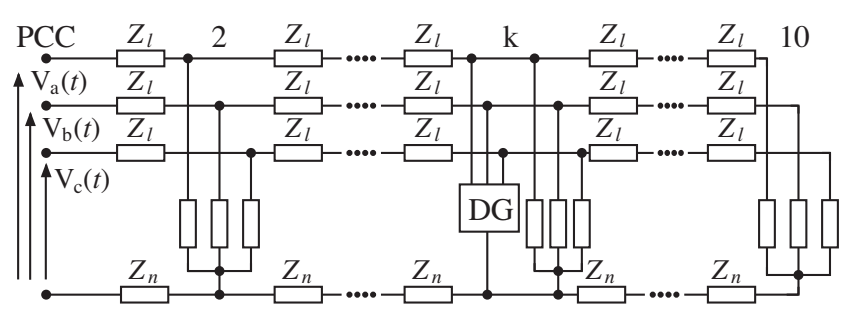

Fig. 1. Simplified three-phase radial network with three-phase DG unit.

behaviour towards the zero-sequence and negative-sequence component of the grid voltage. This can be translated into the following equations:

$\left[\begin{array}{l}\underline{i}_{0} \\ \underline{i}_{1} \\ \underline{i}_{2}\end{array}\right]=\left[\begin{array}{ccc}g_{\mathrm{d}} & 0 & 0 \\ 0 & g_{1} & 0 \\ 0 & 0 & g_{\mathrm{d}}\end{array}\right]\left[\begin{array}{l}\underline{v}_{0} \\ \underline{v}_{1} \\ \underline{v}_{2}\end{array}\right]$

Eq. (10) can be transformed to phase values by:

$\left[\begin{array}{l}\underline{i}_{a} \\ \underline{i}_{b} \\ \underline{i}_{c}\end{array}\right]=T^{-1}\left[\begin{array}{ccc}g_{\mathrm{d}} & 0 & 0 \\ 0 & g_{1} & 0 \\ 0 & 0 & g_{\mathrm{d}}\end{array}\right] T\left[\begin{array}{l}\underline{v}_{a} \\ \underline{v}_{b} \\ \underline{v}_{c}\end{array}\right]$

with $T$ the transformation matrix.

Doing this, the following equations are obtained:

$\underline{i}_{a}=\frac{1}{3}\left\{\underline{v}_{a}\left(g_{1}+2 g_{\mathrm{d}}\right)+a \underline{v}_{b}\left(g_{1}-g_{\mathrm{d}}\right)+a^{2} \underline{v}_{c}\left(g_{1}-g_{\mathrm{d}}\right)\right\}$

$\underline{i}_{b}=\frac{1}{3}\left\{a^{2} \underline{v}_{a}\left(g_{1}-g_{\mathrm{d}}\right)+\underline{v}_{b}\left(g_{1}+2 g_{\mathrm{d}}\right)+a \underline{v}_{c}\left(g_{1}-g_{\mathrm{d}}\right)\right\}$

$\underline{i}_{c}=\frac{1}{3}\left\{a \underline{v}_{a}\left(g_{1}-g_{\mathrm{d}}\right)+a^{2} \underline{v}_{b}\left(g_{1}-g_{\mathrm{d}}\right)+\underline{v}_{c}\left(g_{1}+2 g_{\mathrm{d}}\right)\right\}$

with $a=\exp (j(2 \pi / 3))$.

Harmonic distortion and transients will not be considered in this paper such that $\underline{v}_{x}$ can be written in complex form as:

$\underline{v}_{x}=\left|\underline{v}_{x}\right| \exp \left(j \theta_{x}\right)$

with $\left|\underline{v}_{x}\right|$ the amplitude of $\underline{v}_{x}$ and $\theta_{x}$ its phase angle. If (13) is subsituted in (12), the following equations are obtained:

$\underline{i}_{a}=\frac{1}{3}\left\{\left|\underline{v}_{a}\right| \exp \left(j \theta_{a}\right)\left(g_{1}+2 g_{\mathrm{d}}\right)+\left[\underline{v}_{b} \mid \exp \left(j\left(\theta_{b}+\frac{2 \pi}{3}\right)\right)\right.\right.$

$\left.\left.+\left|\underline{v}_{c}\right| \exp \left(j\left(\theta_{c}-\frac{2 \pi}{3}\right)\right)\right]\left(g_{1}-g_{\mathrm{d}}\right)\right\}$

$\underline{i}_{b}=\frac{1}{3}\left\{\left|\underline{v}_{b}\right| \exp \left(j \theta_{b}\right)\left(g_{1}+2 g_{\mathrm{d}}\right)+\left[\underline{v}_{a} \mid \exp \left(j\left(\theta_{a}-\frac{2 \pi}{3}\right)\right)\right.\right.$

$\left.\left.+\left|\underline{v}_{c}\right| \exp \left(j\left(\theta_{c}+\frac{2 \pi}{3}\right)\right)\right]\left(g_{1}-g_{\mathrm{d}}\right)\right\}$

$\underline{i}_{c}=\frac{1}{3}\left\{\left|\underline{v}_{c}\right| \exp \left(j \theta_{c}\right)\left(g_{1}+2 g_{\mathrm{d}}\right)+\left[\left|\underline{v}_{a}\right| \exp \left(j\left(\theta_{a}+\frac{2 \pi}{3}\right)\right)\right.\right.$

$\left.\left.+\left|\underline{v}_{b}\right| \exp \left(j\left(\theta_{b}-\frac{2 \pi}{3}\right)\right)\right]\left(g_{1}-g_{\mathrm{d}}\right)\right\}$

\section{Simulation model}

The effect of the four above-described control strategies on voltage unbalance is examined by performing a power flow analysis on a three-phase four-wire distribution network where the neutral conductor is taken into account. The model allows to compute the voltages and currents in the distribution feeder as a function of the voltage at the PCC (cf. Fig. 1). The power flow problem is solved using the forward/backward method where the inverter is modelled as a voltage-dependent current source. More detailed information about the power flow problem solver used in this paper can be found in [11]. 


\subsection{Description of the basic distribution network}

Fig. 1 depicts the basic topology of the three-phase distribution network which will be used for simulation. In each node a load or a DG unit can be connected, single or three-phase loads or DG-units are possible. The loads are simulated as constant-impedance. The impedance of the line conductor is chosen equal to the impedance of the neutral conductor. The impedance of the line conductor is $Z_{l}=(0.265+0.078 j) \Omega / \mathrm{km}$ which corresponds with a typical Belgian suburban distribution network.

\subsection{Model of the dc-bus voltage controller}

The first step in the power flow solver method is the calculation of the voltage at the different nodes of the distribution feeder. When the voltage at the node of the DG unit is calculated, the injected currents are calculated based on the input conductance $g_{1}$ and on the deviation of the voltage to the nominal voltage. These currents will change the voltage at the POC. At this point, the first step in the method is repeated until convergence is reached.

Based on (7) and (14) the injected currents can be divided into two parts, corresponding to $g_{1}$ and $g_{\mathrm{d}}$ respectively. The term determined by $g_{d}$ may correspond with a power transfer. Therefore $g_{1}$ should be adapted by the dc-bus voltage controller [20]. The dcbus voltage controller is modelled as follows: with every step in the iteration, the voltage at the POC changes, requiring a change of $g_{1}$. New values for $g_{1}$ are obtained by using the equations resulting from the power balance between the ac-and dc-side of the inverter.

For the single-phase resistively behaving control strategy this leads to (Section 3.3):

$g_{1}=\frac{p^{\mathrm{DG}}}{\left|\underline{v}_{a}\right|+\left|\underline{v}_{b}\right|+\left|\underline{v}_{c}\right|}+g_{\mathrm{d}}\left[1-\frac{\sum\left|\underline{v}_{x}\right|^{2}}{\sum\left|\underline{v}_{x}\right|}\right]$

For the three-phase damping control strategy (Section 3.4):

$$
\begin{aligned}
g_{1}= & \frac{3 p^{\mathrm{DG}}}{\sum\left|\underline{v}_{x}\right|^{2}+2 \sum_{x \neq y}\left|\underline{v}_{x}\right|\left|\underline{v}_{y}\right| \cos \left(\theta_{x}-\theta_{y}-(2(\pi / 3))\right)} \\
& -2 g_{\mathrm{d}} \frac{\sum\left|\underline{v}_{x}\right|^{2}-\sum_{x \neq y}\left|\underline{v}_{x}\right|\left|\underline{v}_{y}\right| \cos \left(\theta_{x}-\theta_{y}-(2(\pi / 3))\right)}{\sum\left|\underline{v}_{x}\right|^{2}+2 \sum_{x \neq y}\left|\underline{v}_{x}\right|\left|\underline{v}_{y}\right| \cos \left(\theta_{x}-\theta_{y}-(2(\pi / 3))\right)}
\end{aligned}
$$

These two expressions are deduced in Appendix A.

\section{Simulation results}

The influence of the different control strategies on voltage unbalance is studied by using different simulations. In a first simulation a ten node distribution network as depicted in Fig. 1 is studied. This distribution network with unbalanced loads and DGunits will be simulated with one three-phase DG-unit connected. The second simulation will concern the distribution network with two three-phase DG-units, one connected to node 8 and the other to node 10 .

\subsection{One three-phase $D G$ at node 8}

The topology of the ten node network is depicted in Fig. 1. The distribution network has a length of $400 \mathrm{~m}$ and consists of ten nodes. The load distribution is given in Table 2 which shows that the three-phase DG-unit is connected to node 8 . The voltage profile without the three-phase DG-unit in node 8 is depicted in Fig. 2. To evaluate the impact of the control strategies for DG-units on the
Table 2

Load distribution of Simulation A $(P>0$ : load, $P<0$ : DG. $)$

\begin{tabular}{rlcc}
\hline Node & Phase a $[\mathrm{kVA}]$ & Phase b $[\mathrm{kVA}]$ & Phase c $[\mathrm{kVA}]$ \\
\hline 1 & -3 & -3 & -9 \\
2 & 10 & -10 & -3 \\
3 & -3 & -3 & -10 \\
4 & 12 & -3 & -3 \\
5 & -3 & -4 & -7 \\
6 & 7 & -3 & -3 \\
7 & -3 & -3 & -8 \\
8 & $3-$ phase DG & & -9 \\
9 & -3 & -3 & -8 \\
10 & -3 & -3 & \\
\hline
\end{tabular}

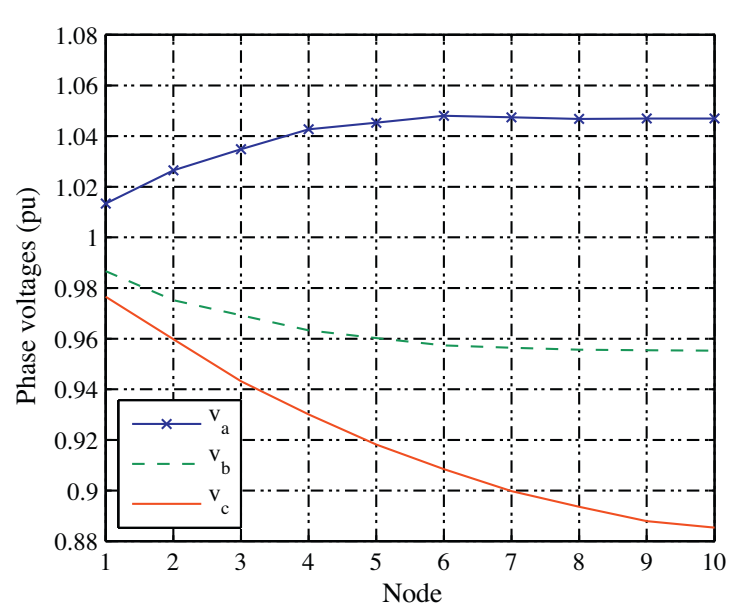

Fig. 2. Voltage profile without DG-units.

voltage unbalance, the three-phase DG-unit is connected at node 8 resulting in four new cases which will be discussed below.

\subsubsection{Positive-sequence component}

The three-phase damping control strategy gives the highest positive-sequence voltage component as depicted in Fig. 3(a). The reason is that the zero-sequence and the negative-sequence power are transferred via the dc-bus into positive-sequence power which results in higher positive-sequence voltage component.

\subsubsection{Zero-sequence component}

The single-phase resistively behaving control strategy and the three-phase damping control strategy result in a significant decrease of the zero-sequence component and of the zerosequence voltage unbalance factor as can be seen in Figs. 4(a) and $5(\mathrm{a})$, respectively.

In case of the single-phase resistively behaving control strategy (9), the zero-sequence component results in:

$\underline{i}_{0}=\frac{1}{3}\left\{\left(g_{1}+1\right)\left[\exp \left(j \theta_{a}\right)+\exp \left(j \theta_{b}\right)+\exp \left(j \theta_{c}\right)\right]-3 \underline{v}_{0}\right\}$

The vector corresponding with $\left[\exp \left(j \theta_{a}\right)+\exp \left(j \theta_{b}\right)+\exp \left(j \theta_{c}\right)\right]$ has in this specific case the same direction as $\underline{v}_{0}$ but is much smaller as $3 \underline{v}_{0}$, which results in the decrease of the zero-sequence component.

The three-phase damping control strategy results in the biggest decrease of the zero-sequence component as can be seen in Fig. 4(a). Instead of injecting zero-sequence current as is the case of the single-phase sinusoidal control strategy (cf (5) and Table 3), the three-phase damping control strategy results in absorbing zerosequence current as can be seen in (10). In case of DG appliciatons $g_{1}$ and $g_{d}$ have opposite signs such that positive-sequence power is injected and zero-sequence power is absorbed. This also has an effect on the voltage profile which will be discussed below. 

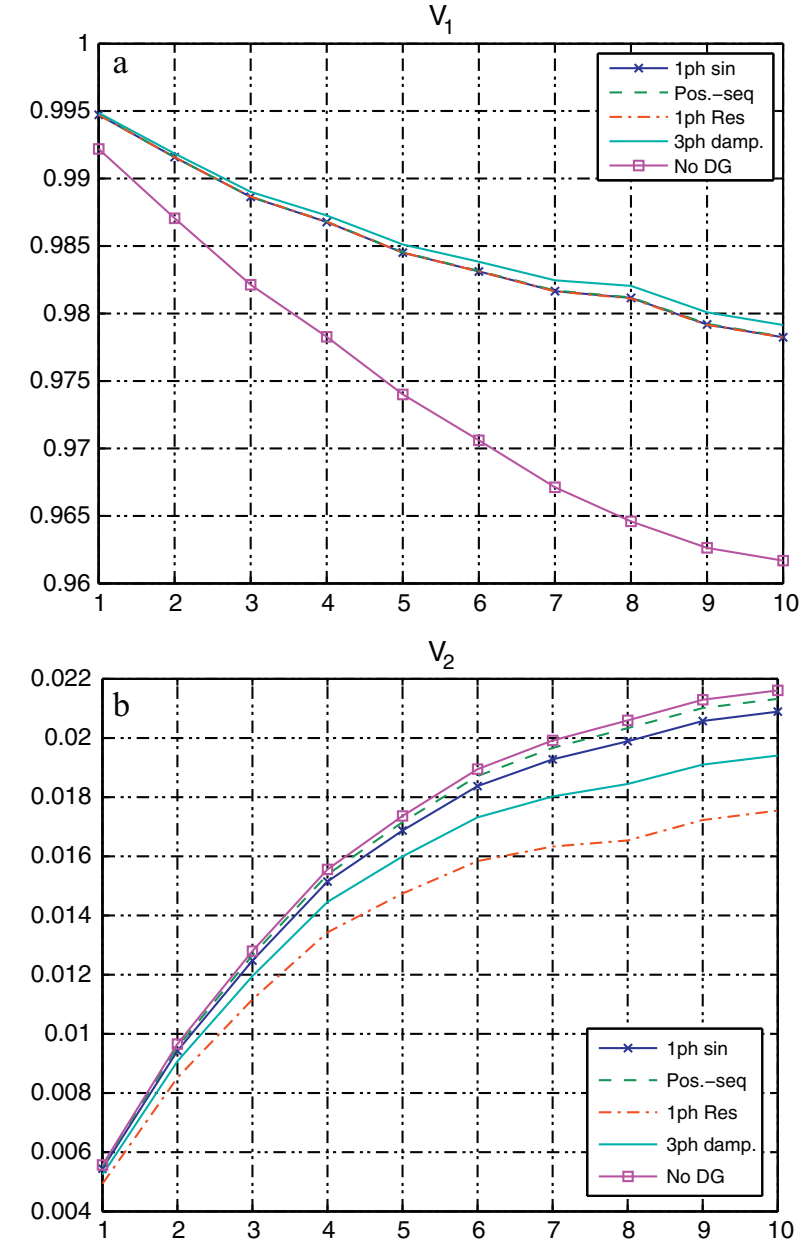

Fig. 3. Simulation A-one three-phase DG-unit at node $8.1 \mathrm{ph}$ sin: single-phase sinusoidal control strategy, Pos.-seq: Positive-sequence control stragey, 1ph Res: single-phase resistively behaving control strategy, 3 ph damp: three-phase damping control strategy.

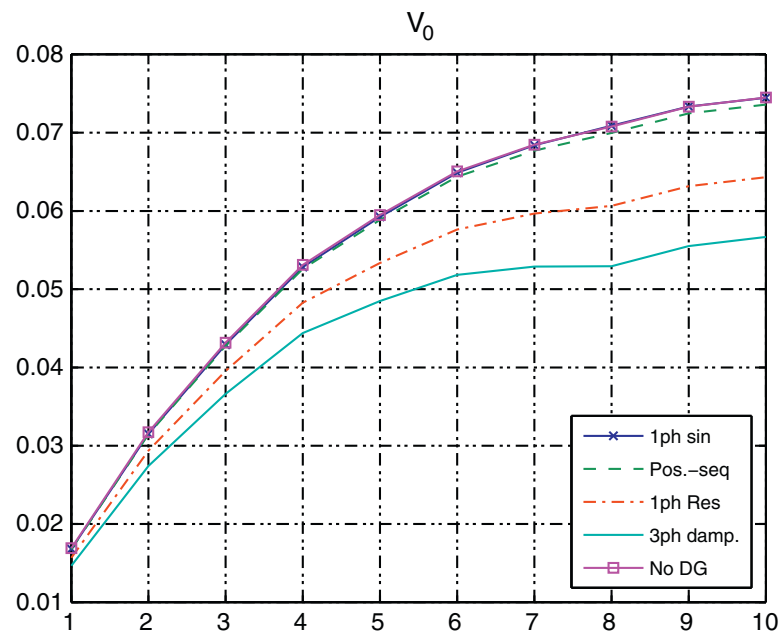

Fig. 4. Simulation A-one three-phase DG-unit at node 8 .

Table 3

Injected currents by the different control strategies [pu]

\begin{tabular}{lll}
\hline & $i_{0}$ & $i_{2}$ \\
\hline 1ph Sin & $-1.75 e^{-5}+\mathrm{j} 1.29 e^{-6}$ & $-1.14 e^{-5}+\mathrm{j} 1.24 e^{-6}$ \\
Pos.-seq. & 0 & 0 \\
1ph Res. & $6.11 e^{-5}-\mathrm{j} 3.12 e^{-5}$ & $8.47 e^{-5}-\mathrm{j} 3.03 e^{-5}$ \\
3ph damp. & $1.10 e^{-4}-\mathrm{j} 4.28 e^{-5}$ & $3.19 e^{-5} \mathrm{j} 3.01 e^{-5}$ \\
\hline
\end{tabular}
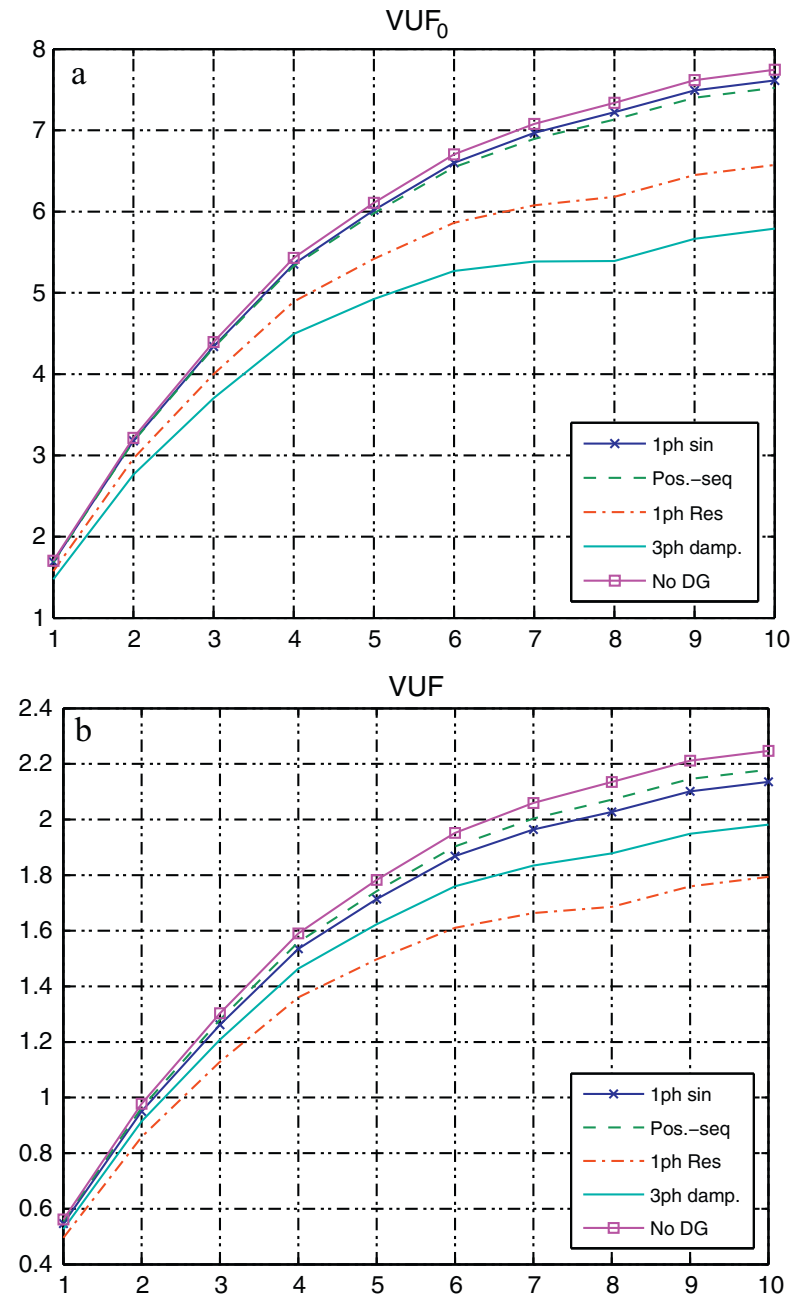

Fig. 5. Simulation A-one three-phase DG-unit at node 8.

The positive-sequence control strategy only injects positivesequence power and thus has the least influence on the zero-sequence or negative-sequence voltage component. The small difference between the positive-sequence control strategy and the case when no DG-unit is caused by the presence of unbalanced loads.

Compared to the positive-sequence control strategy, the zerosequence voltage unbalance factor is increased when the singlephase sinusoidal control strategy is used as can be seen in Fig. 5(a). This can be explained by (5), which results in an increase for the zero-sequence power which is injected in the network and thus an increase of the zero-sequence voltage component at the POC.

\subsubsection{Negative-sequence component}

The negative-sequence voltage component and the voltage unbalance factor are depicted in Figs. 3(b) and 5(b) respectively. The standard EN 50160 (cf Table 1) states that the negative-sequence component of the supply voltage must be lower than $2 \%$ during $95 \%$ of the week. It can be seen in Fig. 5(b) that only the single-phase resistively behaving control strategy and the three-phase damping control strategy result in a decrease of the negative-sequence voltage component such that the required voltage unbalance factor is obtained. This justifies the addition of active power filtering function to the control of inverter-connected DG-units. 

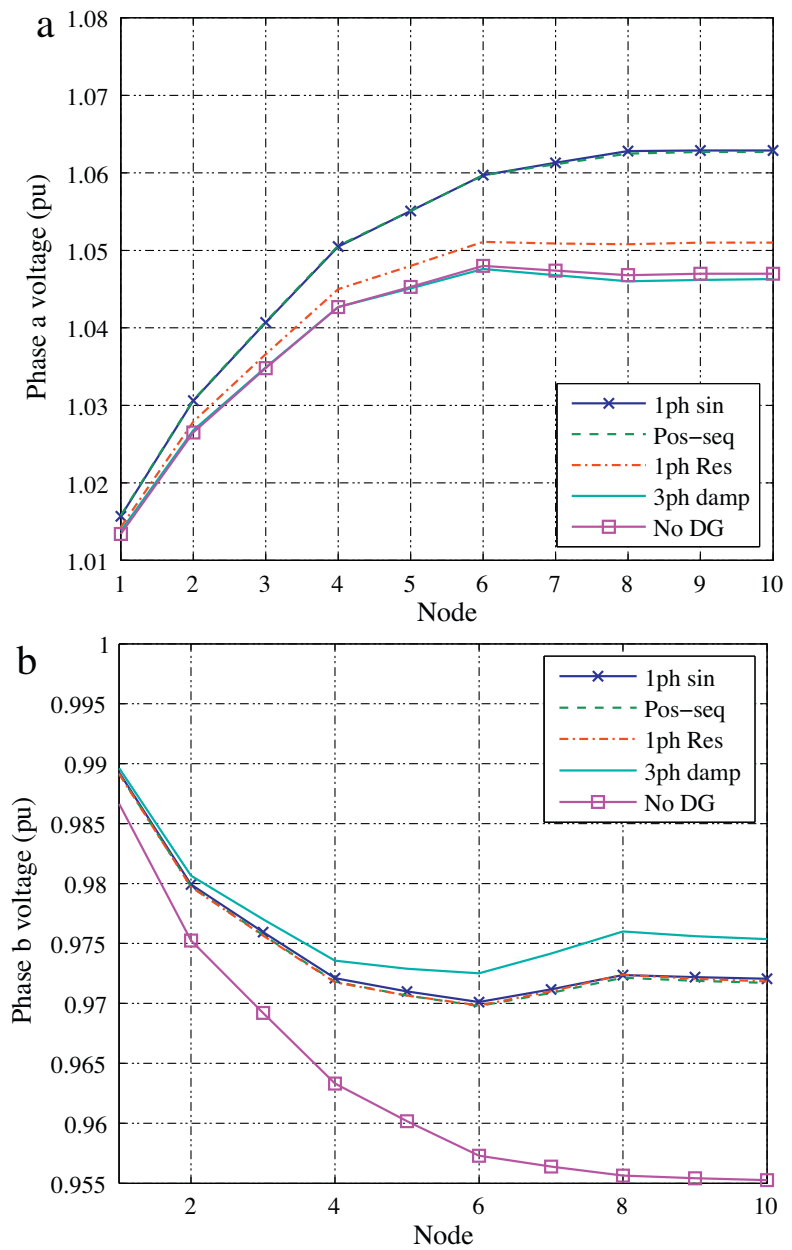

Fig. 6. Simulation A-one three-phase DG-unit at node 8.

\subsubsection{Voltage profile}

The voltage unbalance factor and the zero-sequence voltage unbalance factor provide information about the degree of unbalance. Another interesting parameter is the rms value of the supply voltage at the POC. In Fig. 6(a) the rms value of the voltage of phase a is depicted for the 5 different cases. Figs. 6(b) and 7(a) depict the rms value of phase $b$ and $c$ respectively. It is important that the rms value of the phase voltages is close to the nominal value. In LV net-

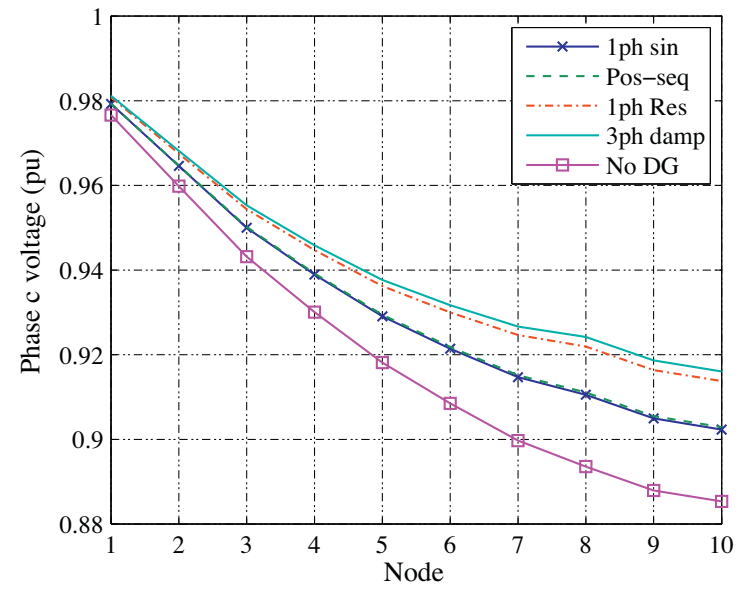

Fig. 7. Simulation A-one three-phase DG-unit at node 8.
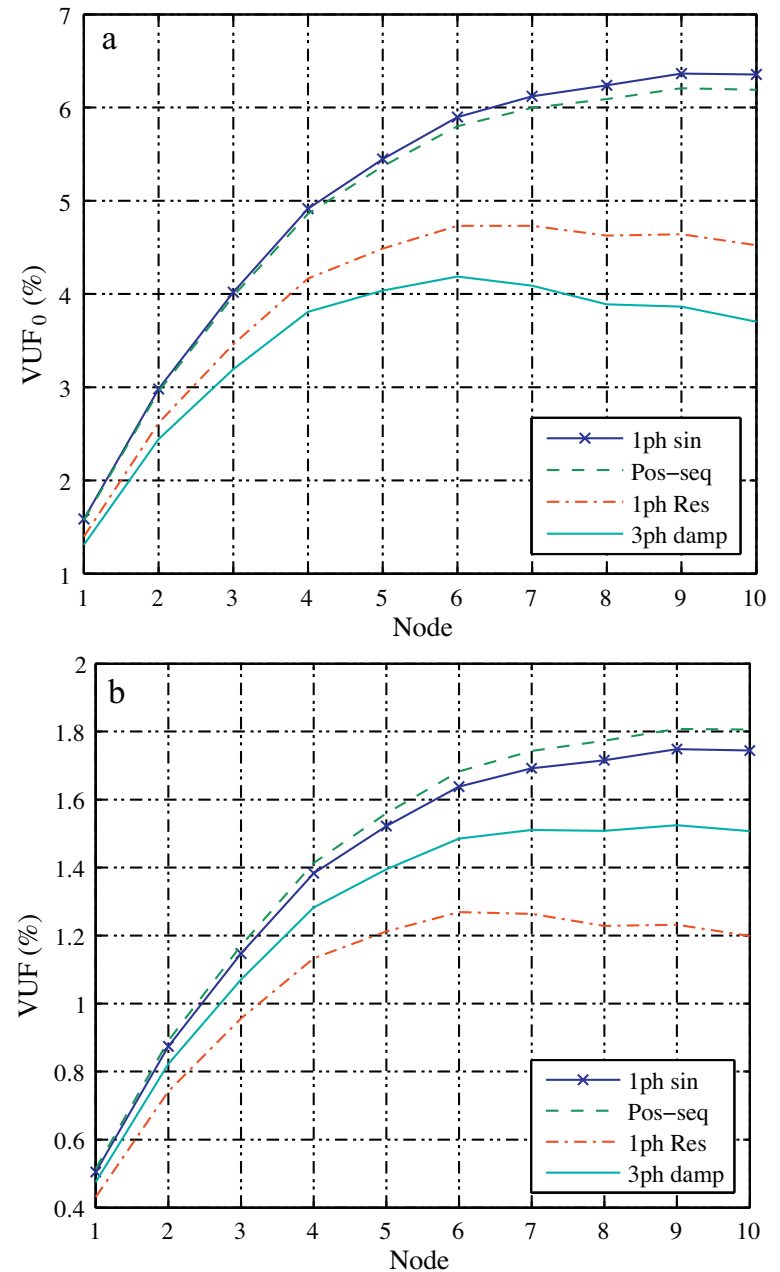

Fig. 8. Simulation A-two three-phase DG-units at node 8 and 10.

works the majority of the loads are single-phase loads which are sensitive to the phase voltage. In Fig. 6 it can be seen that the different control strategies have a different effect on the voltage profile over the feeder. Furthermore the single-phase resistively behaving control strategy and the three-phase damping control strategy lead to best voltage profile. The control strategy which leads to the best voltage profile is, in this case, undoubtedly the three-phase damping control strategy.

Although the single-phase resistively behaving control strategy leads to a higher decrease of the negative-sequence component as compared to the three-phase damping control strategy (cf Fig. 3(b)), the three-phase damping control strategy leads to a voltage profile which is closer to the nominal value. The voltage change caused by the three-phase damping control strategy can be quantified by using the following values for the network as depicted in Fig. 1. The line impedance is $0.018+j 0.0035 \Omega$ for the direct and inverse component, where for the zero-sequence component four times this value has been used. The same current in the zero-sequence network thus results in a voltage change which is four times larger compared to the positive- and negative-sequence component. The different injected currents are shown in Table 3 where it can be seen that both the single-phase resistively behaving control strategy and the three-phase damping controls strategy lead to the absorption of zero-sequence power. Absorbing zero-sequence current improves the voltage profile because the neutral-point is shifted towards the highest loaded phase (in this case between phase a and b) which results in a increase of the phase voltages $b$ and $c$. 

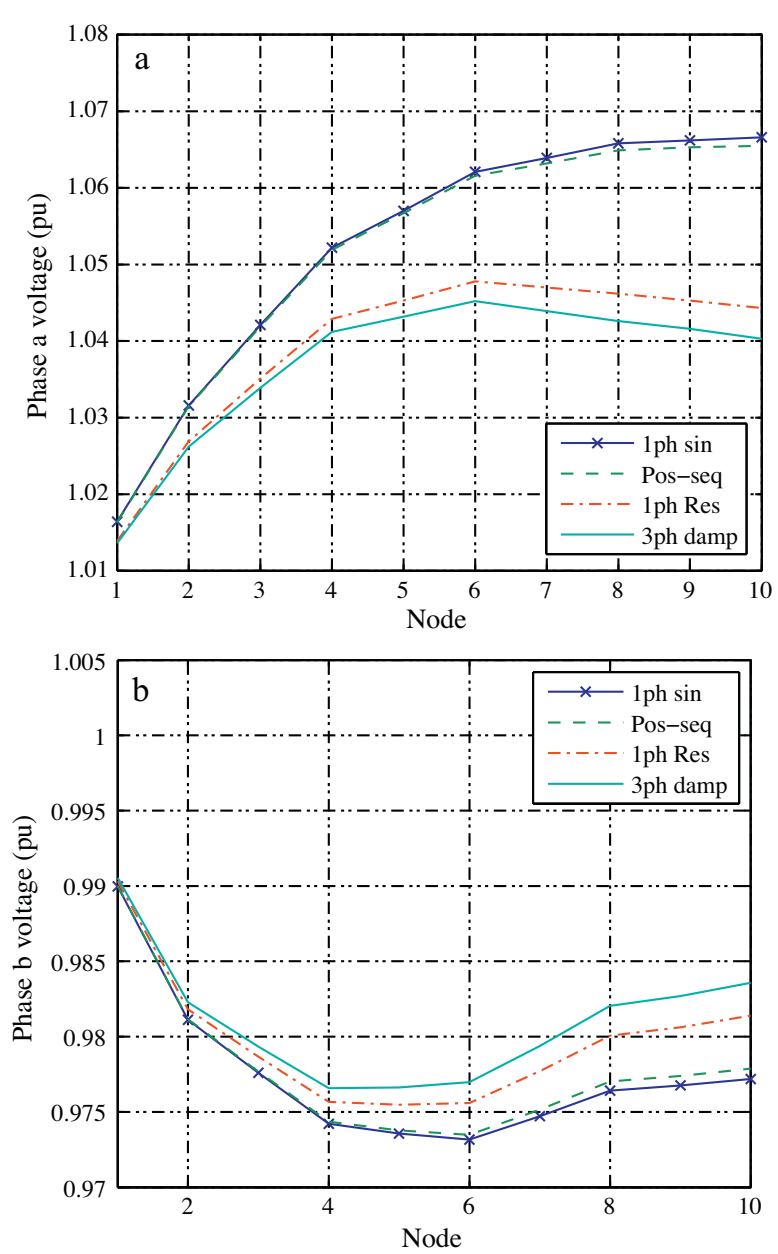

Fig. 9. Simulation A-two three-phase DG-units at node 8 and 10.

The single-phase sinusoidal control strategy results in the injection of zero-sequence power which leads to the neutral-point shifiting. The neutral-point shifts in a way such that voltage profile is decreased (cf Fig. 6) which is caused by the injection of zero-sequence current [10]. As can be seen in Fig. 6(a) the single-phase sinusoidal control strategy results in the highest rms value which is disadvantageous for the distribution network.

It can thus be concluded that the main voltage variation results from the neutral-point shifting caused by the zero-sequence current. A control strategy with a resistive behaviour for the zerosequence component can thus lead to an improved voltage profile. The three-phase damping control strategy has the added advantage that a same amount of power is injected resulting in an improved voltage profile which is benificial for the increase in DG penetration depth in the LV network. The higher decrease of the zero-sequence voltage component due to the three-phase damping control strategy leads to a better voltage profile. This is especially interesting for low voltage distribution networks where the greater part of the loads are single-phase loads which are sensitive to over- or undervoltages (compared to the nominal voltage).

\subsection{Two three-phase DG units at node 8 and 10}

At node 10, another three-phase DG-unit is connected which injects $10 \mathrm{kVA}$. Fig. 8(a) and (b) depict the zero-sequence voltage unbalance factor and the voltage unbalance factor respectively.

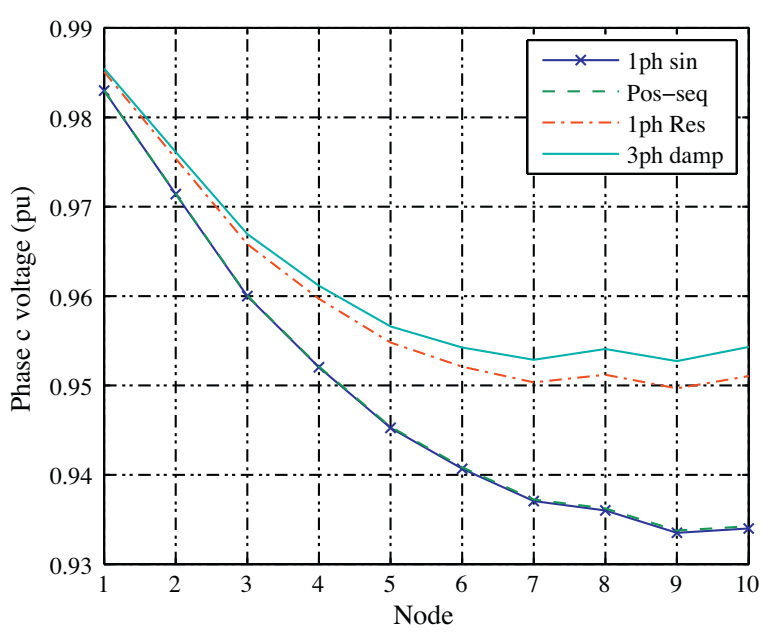

Fig. 10. Simulation A-two three-phase DG-units at node 8 and 10 .

The voltage unbalance is further decreased by connecting another three-phase DG-unit.

In Figs. 9(a), (b) and 10(a) the rms values of the phase voltages a, $b$ and $c$ respectively are depicted. It should be noted that the threephase damping control strategy leads to a further improvement of the voltage profile compared to the three other cases. Using the three-phase damping control strategy in low voltage distribution networks will thus have a beneficial effect on the power quality and especially the voltage profile.

\section{Conclusion}

A three-phase four-wire distribution network is used to study the effect of four different control strategies for three-phase inverter-connected DG-units on voltage unbalance in distribution networks. Both the negative-sequence component and the zerosequence component are studied.

The single-phase resistively behaving control strategy and the three-phase damping control strategy, compared to the singlephase sinusoidal and the positive-sequence control strategy, have the most beneficial effect on voltage unbalance. The three-phase damping control strategy also has a beneficial effect on the voltage profile which is caused by the ability to control the zero-sequence components, which the other control strategies lack. The positive effect of the three-phase damping control strategy on the voltage profile (in case of an unbalanced network) leads to the fact that it can have a positive effect on the increase in DG penetration depth in the LV network. The three-phase damping control strategy allows to integrate more DG-units as compared to the other control strategies. The other control strategies will lead to overvoltages.

When connecting DG units to the grid, it is recommended that the DG is connected by means of a three-phase inverter which is controlled using a three-phase damping control strategy. The inverter will thus inject power in the grid and will help improve voltage unbalance.

\section{Appendix A. Deduction of $g_{1}$ as function of $g_{d}$}

The term by $g_{d}$ in (7) and (14) may correspond with a power transfer. Therefore $g_{1}$ should be adapted by the dc-bus voltage controller. The dc-bus voltage controller is modelled by changing the value for $g_{1}$, the expression for $g_{1}$ is obtained using the power balance between the ac- and dc-side of the inverter. 
Expressing the power balance between ac- and dc-side of the inverter gives:

$\Re\left(\underline{v}_{a} i_{a}^{*}+\underline{v}_{b} \underline{i}_{b}^{*}+\underline{v}_{c} i_{c}^{*}\right)=p^{D G}$

For the single-phase resistively behaving converter the injected currents are given by (7) and as no harmonics nor transients are considered. $\underline{v}_{x}$ can be written as (13) such that (A.1) results in:

$$
\begin{aligned}
p^{D G}= & \Re\left(\left|\underline{v}_{a}\right| \exp \left(j \theta_{a}\right)\left[g_{1}+g_{\mathrm{d}}\left(\left|\underline{v}_{a}\right|-1\right)\right] \exp \left(-j \theta_{a}\right)+\left|\underline{v}_{b}\right| \exp \left(j \theta_{b}\right)\left[g_{1}\right.\right. \\
& \left.+g_{\mathrm{d}}\left(\left|\underline{v}_{b}\right|-1\right)\right] \exp \left(-j \theta_{b}\right)+\left|\underline{v}_{c}\right| \exp \left(j \theta_{c}\right)\left[g_{1}\right. \\
& \left.\left.+g_{\mathrm{d}}\left(\left|\underline{v}_{c}\right|-1\right)\right] \exp \left(-j \theta_{c}\right)\right)
\end{aligned}
$$

which can be written as:

$g_{1}=\frac{p^{\text {DG }}}{\left|\underline{v}_{a}\right|+\left|\underline{v}_{b}\right|+\left|\underline{v}_{c}\right|}+g_{\mathrm{d}}\left[1-\frac{\sum\left|\underline{v}_{x}\right|^{2}}{\sum\left|\underline{v}_{x}\right|}\right]$

For the three-phase damping control strategy the same procedure can be followed. Based on (A.1), (14) and (13) the following expression can be deduced:

$$
\begin{aligned}
p^{D G}= & \Re\left(| \underline { v } _ { a } | \operatorname { e x p } ( j \theta _ { a } ) \frac { 1 } { 3 } \left[\left(g_{1}+2 g_{\mathrm{d}}\right)\left|\underline{v}_{a}\right| \exp \left(-j \theta_{a}\right)\right.\right. \\
& +\left(g_{1}-g_{\mathrm{d}}\right)\left|\underline{v}_{b}\right| \exp \left(-j\left(\theta_{b}+\frac{2 \pi}{3}\right)\right) \\
& \left.+\left(g_{1}-g_{\mathrm{d}}\right)\left|\underline{v}_{c}\right| \exp \left(j\left(-\theta_{c}+\frac{2 \pi}{3}\right)\right)\right] \\
& +\left|\underline{v}_{b}\right| \exp \left(j \theta_{b}\right) \frac{1}{3}\left[\left(g_{1}-g_{\mathrm{d}}\right)\left|\underline{v}_{a}\right| \exp \left(j\left(-\theta_{a}+\frac{2 \pi}{3}\right)\right)+\left(g_{1}\right.\right. \\
& \left.\left.+2 g_{\mathrm{d}}\right)\left|\underline{v}_{b}\right| \exp \left(-j \theta_{b}\right)+\left(g_{1}-g_{\mathrm{d}}\right)\left|\underline{v}_{c}\right| \exp \left(-j\left(\theta_{c}+\frac{2 \pi}{3}\right)\right)\right] \\
& +\left|\underline{v}_{c}\right| \exp \left(j \theta_{c}\right) \frac{1}{3}\left[\left(g_{1}-g_{\mathrm{d}}\right)\left|\underline{v}_{a}\right| \exp \left(-j\left(\theta_{a}+\frac{2 \pi}{3}\right)\right)\right. \\
& +\left|\underline{v}_{b}\right|\left(g_{1}-g_{\mathrm{d}}\right) \exp \left(j\left(-\theta_{b}+\frac{2 \pi}{3}\right)\right) \\
& \left.\left.+\left(g_{1}+2 g_{\mathrm{d}}\right)\left|\underline{v}_{c}\right| \exp \left(-j \theta_{c}\right)\right]\right)
\end{aligned}
$$

After using the inverse Simpson equations and some basic calculus the following expression is obtained:

$$
\begin{aligned}
g_{1}= & \frac{3 p^{\mathrm{DG}}}{\sum\left|\underline{v}_{x}\right|^{2}+2 \sum_{x \neq y}\left|\underline{v}_{x}\right|\left|\underline{v}_{y}\right| \cos \left(\theta_{x}-\theta_{y}-2(\pi / 3)\right)} \\
& -2 g_{\mathrm{d}} \frac{\sum\left|\underline{v}_{x}\right|^{2}-\sum_{x \neq y}\left|\underline{v}_{x}\right|\left|\underline{y}_{y}\right| \cos \left(\theta_{x}-\theta_{y}-2(\pi / 3)\right)}{\sum\left|\underline{v}_{x}\right|^{2}+2 \sum_{x \neq y}\left|\underline{v}_{x}\right|\left|\underline{v}_{y}\right| \cos \left(\theta_{x}-\theta_{y}-2(\pi / 3)\right)}
\end{aligned}
$$

\section{References}

[1] Voltage characteristics of electricity supplied by public distribution systems, 1999.

[2] H. Akagi, Control strategy and site selection of a shunt active filter for damping of harmonic propagation in power distribution systems, IEEE Trans. Power Del. 12 (January 1) (1997) 354-363.

[3] H. Akagi, Y. Kanazawa, A. Nabae, Instantaneous reactive power compensators comprising switching devices without energy storage, IEEE Trans. Ind. Appl. 20 (May/June 3) (1984) 625-703.

[4] S. Alepuz, S. Busquets-Monge, J. Bordonau, J. Cago, D. Gonźalez, J. Belcells, Interfacing renewable energy sources to the utility grid using a three-level inverter, IEEE Trans. Ind. Electron. 53 (October 5) (2006) 1504-1511.

[5] H. Becker, G. Cramer, S. Bremicker, T. Dingel, B. Engel, W. Groote, F. Greizer, J. Laschinski, M., Victor, T. Westphal, Method for converting direct voltage into three-phase alternating voltage, August 2007.

[6] M.H.J. Bollen, Definitions of voltage unbalance, IEEE Power Eng. Rev. 22 (November 11) (2002) 49-50.
[7] S. Bremicker, F. Greizer, J. Laschinski, M. Victor, P. Simon, Photovoltaikanlage zur dreiphasigen einspeisung in ein elektrisches energieversorgungsnetz, August 2010.

[8] J.M. Carrasco, L.G. Franquelo, J.T. Bialasiewicz, E. Galván, R.C.P. Guisado, M.A.M. Prats, J.I. León, N. Moreno-Alfonso, Power-electronic systems for the grid integration of renewable energy sources: A survey, IEEE Trans. Ind. Electron. 53 (August 4) (2006) 1002-1016.

[9] M. Dai, M.N. Marwali, J.-W. Jung, A. Keyhani, A three-phase four-wire inverter control technique for a single distributed generation unit in island mode, IEEE Trans. Power Electron. 23 (January 1) (2008) 322-331.

[10] L. Degroote, B. Renders, B. Meersman, L. Vandevelde, Neutral-point shifting and voltage unbalance due to single-phase dg units in low voltage distribution networks, in: Proc. of International Conference on Electric Power Engineering (Power Tech) 2009, Bucharest, Romania, 2009.

[11] L. Degroote, L. Vandevelde, B. Renders, Fast harmonic simulation method for the analysis of network losses with converter-connected distributed generation, Electric Power Syst. Res. 80 (November 11) (2010) 1332-1340.

[12] J.J. Desmet, I. Sweertvaegher, G. Vanalme, K. Stockman, R.J.M. Belmans, Analysis of the neutral conductor current in a three-phase supplied network with nonlinear single-phase loads, IEEE Trans. Ind. Appl. 39 (May 3) (2003) 587-593.

[13] D. Graovac, V.A. Katić, A. Rufer, Power quality problems compensation with universal power quality conditioning system, IEEE Trans. Power Del. 22 (April 2) (2007) 968-976

[14] T. Green, J. Marks, Control techniques for active power filters, IEE Proc. Electr. Power Appl. 152 (March 2) (2005) 369-381.

[15] B. Han, B. Bae, H. Kim, S. Baek, Combined operation of unified power-quality conditioner with distributed generation, IEEE Trans. Power Del. 21 (January 1 ) (2006) 330-338.

[16] W. Kersting, W. Phillips, Phase frame analysis of the effects of voltage unbalance on induction motors, IEEE Trans. Ind. Appl. 33 (April 2) (1997) 415-420

[17] C.-Y. Lee, Effects of unbalanced voltage on the operation performance of a threephase induction motor, IEEE Trans. Energy Convers. 14 (June 2)(1999) 202-208.

[18] B. Meersman, J.D. Kooning, T. Vandoorn, L. Degroote, B. Renders, L. Vandevelde Overview of PLL methods for distributed generation units, in: Proc. of Universities Power Engineering Conference (UPEC) 2010, Cardiff, United Kingdom, September 1-3, 2010.

[19] B. Meersman, B. Renders, L. Degroote, T. Vandoorn, J.D. Kooning, L. Vandevelde, Overview of three-phase inverter topologies for distributed generation purposes, in: Proc. of the 2nd International Conference on Innovation for Sustainable Production 2010 (iSUP 2010), Bruges, Belgium, April 18-21, 2010.

[20] B. Meersman, B. Renders, L. Degroote, T. Vandoorn, L. Vandevelde, DC-bus voltage controllers for a three-phase voltage-source inverter for distributed generation, in: Proc. of International Conference on Renewable Energy and Power Quality (ICREPQ) 2009, Valencia, Spain, 2009.

[21] P. Pillay, M. Manyage, Definitions of voltage unbalance, IEEE Power Eng. Rev. 21 (May 5) (2001) 49-51.

[22] E. Power Electronics Applications Center, 1996, Input performance of ASDs during supply voltage unbalance, No. Brief 28 , Power quality testing network PQTN.

[23] M. Prodanović, T. Green, Control and filter design of three-phase inverters for high power quality grid connection, IEEE Trans. Power Electron. 18 (January 1) (2003) 373-380.

[24] M. Prodanović, T. Green, High-quality power generation through distributed control of a power park microgrid, IEEE Trans. Ind. Electron. 53 (October 5) (2006) 1471-1482.

[25] B. Renders, K. De Gussemé, W.R. Ryckaert, L. Vandevelde, Converter-connected distributed generation units with integrated harmonic voltage damping and harmonic current compensation function, Electric Power Syst. Res. 79 (1) (Jan. 2009) 65-70.

[26] B. Renders, W.R. Ryckaert, K. De Gussemé, K. Stockman, L. Vandevelde, Improving the voltage dip immunity of converter-connected distributed generation units, Renew. Energy 33 (May 5) (2008) 1011-1018.

[27] J. Rodríguez, J.-S. Lai, F.Z. Peng, Multilevel inverters: A survey of topologies, controls and applications, IEEE Trans. Ind. Electron. 49 (August 4) (2002) 724-738.

[28] L. Sainz, J. Pedra, J.J. Mesas, Study of neutral conductor current in three-phase networks with single-phase converters, IEEE Trans. Power Del. 21 (July 3) (2006) 1466-1476.

[29] H.-S. Song, K. Nam, Dual current control scheme for PWM converter under unbalanced input voltage conditions, IEEE Trans. Power Electron. 8 (October 5) (1999) 953-959.

[30] A. Timbus, M. Liserre, R. Teodorescu, P. Rodriguez, F. Blaabjerg, Independent synchronization and control of three phase grid converters, in: Proc. of the International Symposium on Power Electronics, Electrical Drives, Automation and Motion (SPEEDAM), 2006, Naples, Italy, May 23-26, 2006.

[31] A. Timbus, M. Liserre, R. Teodorescu, P. Rodriguez, F. Blaabjerg, PLL algorithm for power generation systems robust to grid voltage faults, in: Proc. of the 37th IEEE Power Electronics Specialist Conference (PESC 2006), 2006, Cheju Isl, South Korea, Jun. 18-22, 2006

[32] A. von Jouanne, B. Ben Banerjee, Assessment of voltage unbalance, IEEE Trans Power Del. 16 (October 4) (2001) 782-790.

[33] F. Wang, J. Duarte, M. Hendrix, Reconfiguring grid-interfacing converters for power quality improvement, in: Proc. of International Conference on Renewable Energy and Power Quality (ICREPQ) 2008, Santander, Spain, 2008.

[34] A. Yazdani, R. Iravini, A unified dynamic model and control for the voltagesourced converter under unbalanced grid conditions, IEEE Trans. Power Del. 21 (July 3) (2006) 1620-1629. 